\title{
Modelling Mixed Bed lon Exchange Kinetics for Removal of Trace Levels of Divalent Cations in Ultrapure Water
}

B. Widman

This report was prepared as an account of work sponsored by the United States Government. Neither the United States, nor the United States Department of Energy, nor any of their employees, nor any of their contractors, subcontractors, or their employees, makes any warranty, express or implied, or assumes any legal liability or responsibility for the accuracy, completeness or usefulness of any information, apparatus, product or process disclosed, or represents that its use would not infringe privately owned rights. 


\title{
MODELLING MIXED BED ION EXCHANGE KINETICS FOR REMOVAL OF TRACE LEVELS OF DIVALENT CATIONS IN ULTRAPURE WATER
}

\author{
B. WIDMAN \\ Lockheed Martin Corporation \\ 2401 River Road, Niskayuna, NY 12309-1103, USA
}

\section{INTRODUCTION}

Ion exchanger resin fluid film mass transfer coefficients and the ionic diffusivities from which they are derived are often measured by use of ion exchange resin columns. Such tests, usually run dynamically using short resin beds, are often performed using relatively high (ppm) concentrations of ions to accurately measure output concentrations as a function of flow rate. The testing described herein was performed to determine fluid film ionic diffusivities for cationic concentrations typical of ultrapure water $(\leq \mathrm{ppb}$ levels) containing ppm levels of ammonia. Effective ionic diffusivities at these low ionic concentrations and high $\mathrm{pHs}$ were needed to complete a computer model (SIMIX) to be used in ion exchange simulations. SIMIX is a generalized multicomponent ion exchange model designed to simulate the removal of divalent cations from ultrapure water.

\section{TEST METHODS}

Laboratory closed loop column testing was performed to simulate the collection of divalent metallic corrosion products. The experimental apparatus consisted of three supply columns $(25 \mathrm{~mm} \times 300 \mathrm{~mm})$ containing cation resin converted to iron, nickel, and cobalt forms, respectively. Flow through the columns at about $90 \mathrm{ml} / \mathrm{min}$ resulted in low $\mathrm{ppb}$ concentrations in the effluent of each column. Effluents from all three columns were combined in a header leading to a collection column $(25 \mathrm{~mm} \times 900 \mathrm{~mm})$ containing stoichiometrically equivalent amounts of mixed cation and anion resin. Temperature was maintained at about $32^{\circ} \mathrm{C}$ during the test.

After six months of continuous operation, the collection column was removed from service and the resin bed was carefully divided into about twenty $20-\mathrm{ml}$ aliquots. To characterise the concentration profiles of each metal within the bed, the resin aliquots were eluted numerous times with concentrated nitric acid until essentially all exchanged cations were removed from the resin and collected in the combined eluant. The eluant from each aliquot was subsequently concentrated and then analysed for metals concentration by graphite furnace atomic absorption (GFAA). The metals data were then reduced to determine end-of-test metals concentration in each resin aliquot and analysed by a locally developed kinetic computer model. Linear regression was performed on the resin profile data for each ionic constituent to obtain best-fit values for mass transfer coefficient and effective ionic diffusivity. 


\section{Construction}

The test loop was constructed from stainless steel materials and consisted of a 100 liter feed tank (Feldmier Equipment) connected to a variable speed pump (model 120, Cole Palmer) to recirculate the feed solution through the resin columns. The feed tank was heated by a 120 -watt drum heater, which had a self-contained controller. A thermocouple feedback loop was in place to turn off the power to the band heater if the internal solution temperature exceeded 120F. The resin under study was housed in a glass column $(25 \mathrm{~mm}$ x $900 \mathrm{~mm}$, Ace Glass) mounted vertically on the test loop. The end caps for the resin columns were constructed from polypropylene (Ace Glass) and contained a 100 micron screen to retain the resin beads. Three supply columns ( $25 \mathrm{~mm}$ x $300 \mathrm{~mm}$, Ace Glass) respectively containing nickel form, cobalt form and iron form cation resin were connected in parallel and used to supply the cleanup column containing mixed bed $\left(\mathrm{NH}_{4}{ }^{+} \mathrm{OH}^{-}\right)$resin in a $60 \% / 40 \%$ volumetric mixture. The supply column cation resins were prepared by repetitive dosing of ammonium form cation resin (IWT-WR-4) with concentrated cation salt solutions (e.g. $\mathrm{FeCl}_{2} \bullet 4 \mathrm{H}_{2} \mathrm{O}$ ) until 90 - 100 percent conversion was achieved. The iron conversion was performed under nitrogen to prevent oxidation of the ferrous ions. The three supply columns were prepared by combining the cation form resin and hydroxide form anion resin (R \& H IRW-78) in a 60/40 mixture by volume.

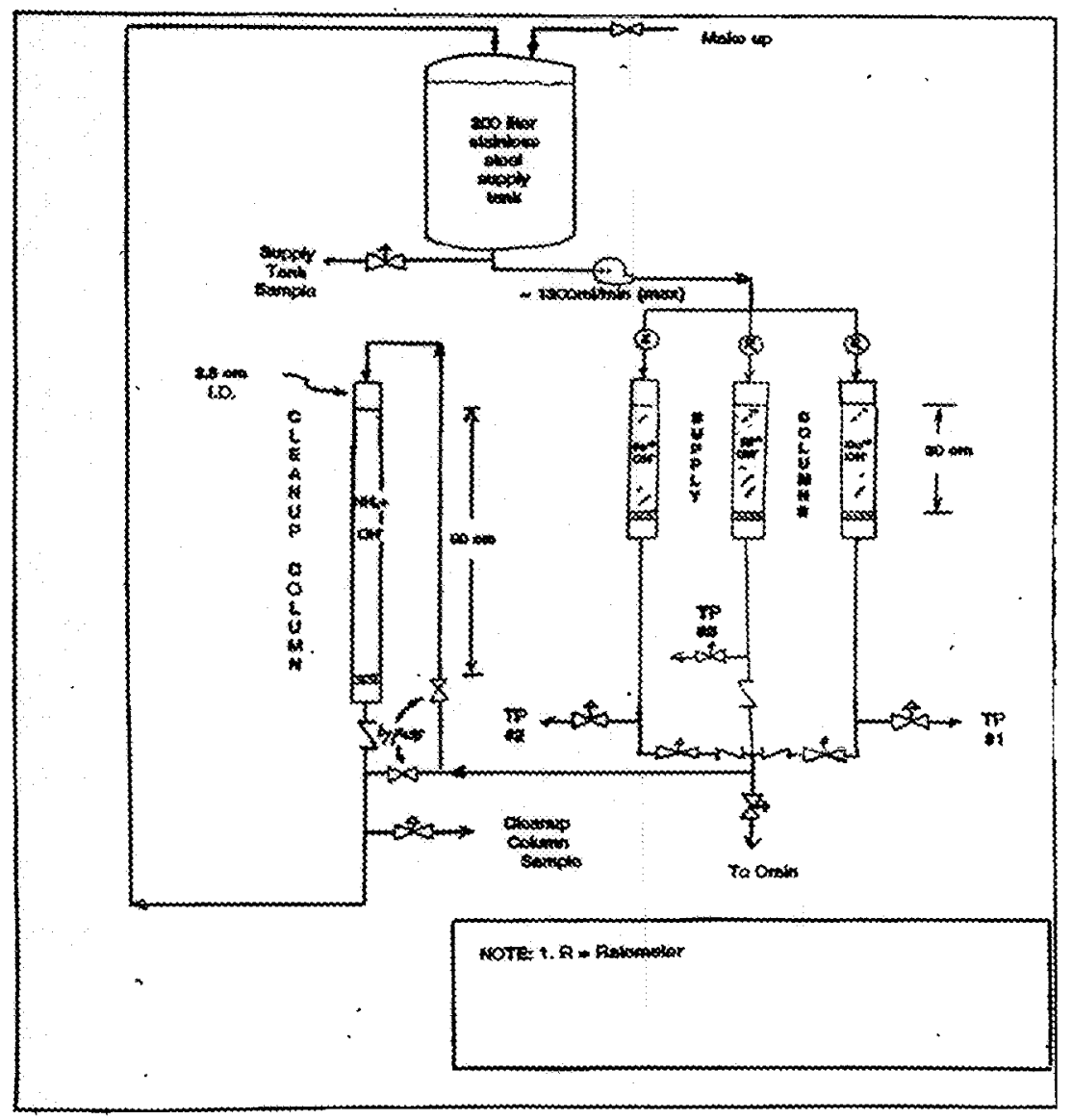

Figure 1 Resin test loop schematic 
The glass cleanup test column filled with ammonium hydroxide resin was placed between the supply columns and the feed tank. The cleanup column was prepared by combining ammonium form cation resin (IWT-WR-4) and hydroxide form anion resin (R \& H IRW78 ) in a 60/40 mixture by volume. This column removed supply column cations before returning the test solution back to the tank. Characteristics of the cleanup column resin are shown on Table 1. The test loop is depicted schematically on Figure 1.

\begin{tabular}{|l|c|}
\hline Type of resin & mixed bed (NHA ${ }^{+}, \mathrm{OH}^{\top}$ forms) \\
\hline cation/anion volume ratio & $0.4 / 0.6$ \\
\hline cation/anion mass ratio & $0.431 / 0.569$ \\
\hline cation/anion true wet density $(\mathrm{g} / \mathrm{ml})$ & $1.26 / 1.11$ \\
\hline resin bead composite wet density $(\mathrm{g} / \mathrm{ml})$ & 1.17 \\
\hline resin bead water fraction & 0.55 \\
\hline resin bed void fraction & 0.3 \\
\hline resin bed bulk density $(\mathrm{g} / \mathrm{ml})($ drained) & 0.819 \\
\hline bed diameter $(\mathrm{cm})$ & 2.5 \\
\hline bed height $(\mathrm{cm})$ & 90 \\
\hline bed volume $(\mathrm{m})$ & 442 \\
\hline bed flow rate $(\mathrm{ml} / \mathrm{min})$ & 268 \\
\hline
\end{tabular}

Table 1 Characteristics of the cleanup column resin and resin bed

\subsection{Operation}

Loop water flow was from a 100 liter stainless steel supply tank, through the three supply column / multiple ion test column assemblies, and then back into the supply tank. Ammoniated doubly deionized water was used as the feed tank solution for all testing in the loop. Oxygen was excluded from the test loop by sparging the feed water with nitrogen and maintaining an overpressure of 5 psig nitrogen on the feed tank at all times. The feed tank solution temperature was maintained between 85 and $97 \mathrm{~F}$ at all times.

The supply columns were sampled through a valve at the base of each column. To maintain the proper flow through the column during sampling, adjustments were made to a valve on the inlet side of each column. Three $50 \mathrm{ml}$ samples were taken from each column with the last $50 \mathrm{ml}$ sample saved for analysis. The sample was acidified with high purity nitric acid and stored in a pre-leached polyethylene bottle. After the sample had been collected the proper flow rate was re-established within the column. Samples were taken directly from the feed tank to determine the feed tank solution $\mathrm{pH}$.

\subsection{Solution Analysis}

Metal analyses were performed using a graphite furnace atomic absorption instrument (Perkin Elmer 5100). Accuracy is $\pm 10 \%$. Minimum detectable activities $(98 \%$ confidence level) for the metals analyses were as follows:

$$
\begin{aligned}
& \text { nickel }=0.65 \mathrm{ppb} \\
& \text { cobalt }=0.54 \mathrm{ppb}
\end{aligned}
$$




$$
\text { iron }=0.48 \mathrm{ppb}
$$

All sample vials and pipette tips used for the analysis had been pre-leached in $10 \% \mathrm{HNO}_{3}$ and stored in $0.1 \mathrm{M} \mathrm{HNO}_{3}$.

\section{$4 \quad$ RESIN COLUMN TEST RESULTS}

Testing was conducted with nickel and hydroxide form resins in supply column \#1, cobalt and hydroxide form resins in supply column $\# 2$, and ferrous and hydroxide form resins in supply column \#3. At the end of 180 days of testing, the test cleanup column was sectioned into approximately twenty units of varying size with the number one unit denoting the top of the column. Each resin section was treated with approximately $1.5 \mathrm{M}$ $\mathrm{HNO}_{3}$ and allowed to equilibrate for a minimum of 24 hours. The supernate was then removed and analyzed for its metals content. Fresh acid was placed on the resin and the cycle repeated until the overall metal mass of the supernate did not change by more than ten percent. The supernate solutions for a resin unit were then combined and analyzed to determine the total nickel, cobalt and iron content of that unit.

The average nickel, cobalt and iron concentration values in water influent to the cleanup column are computed from the resin sectioning and analysis data and the flow rate data as follows:

Total Integrated Flow $=(268 \pm 8) \mathrm{ml} / \mathrm{min} . \times 180$ days $\times 1440 \mathrm{~min} . /$ day $=69,466 \pm 20701$

Avg. cation concentration $=$ cation mass on resin $/$ integrated column flow

Avg. cobalt concentration $=97,995 \mathrm{ug} / 69,4661=1.41 \mathrm{ppb}$

Avg. nickel concentration $=16,838 \mathrm{ug} / 69,4661=0.24 \mathrm{ppb}$

Avg. iron concentration $=55,770 \mathrm{ug} / 69,466 \mathrm{l}=0.80 \mathrm{ppb}$

\section{COMPUTER PROGRAM DESCRIPTION}

This model (SIMIX) is a reversible adsorption model that uses Langmuir isotherm equilibria and film diffusion limited kinetics. The experimental techniques of Reference [1] as modified by Reference [2] were used to build the water phase vs. resin phase equilibrium curves for iron, zinc, cobalt, and nickel. The initial version of the model is described in Reference [3]. Since then, the model has been upgraded to include multicomponent ion exchange modeled by the Markham-Benton equation ${ }^{[4],[5]}$. This equation predicts competitive multicomponent adsorption where the individual species follow Langmuir isotherm equilibria.

As described in Reference [3], the rate of mass transfer between the water phase and resin phase for an individual ionic species (i) proceeds according to Equation (1):

$$
\left.\frac{\partial q_{i}}{\partial t}=\left(k_{L}\right)_{i} \quad a_{p} \quad 1-\frac{q_{i}}{\left(q^{*}\right)_{i}}\right) C_{i}
$$


Flow rate dependent fluid film mass transfer coefficients $(\mathrm{K})$ are calculated from the effective ionic diffusivities according to the correlation developed by Dwivedi and Upadhyay $^{[6]}$, shown in Equation (2).

$$
S h=S c^{\frac{1}{3}} \operatorname{Re}^{\prime}\left[\frac{0.765}{\left(\varepsilon \operatorname{Re}^{\prime}\right)^{0.82}}+\frac{0.365}{}\right]
$$

\section{RESULTS OF COMPUTER SIMULATION}

The resin column sectioning results are presented on Figures 2, 3, and 4. These figures contain semi-log plots of nickel, cobalt, and iron concentrations in each resin unit versus bed depth.

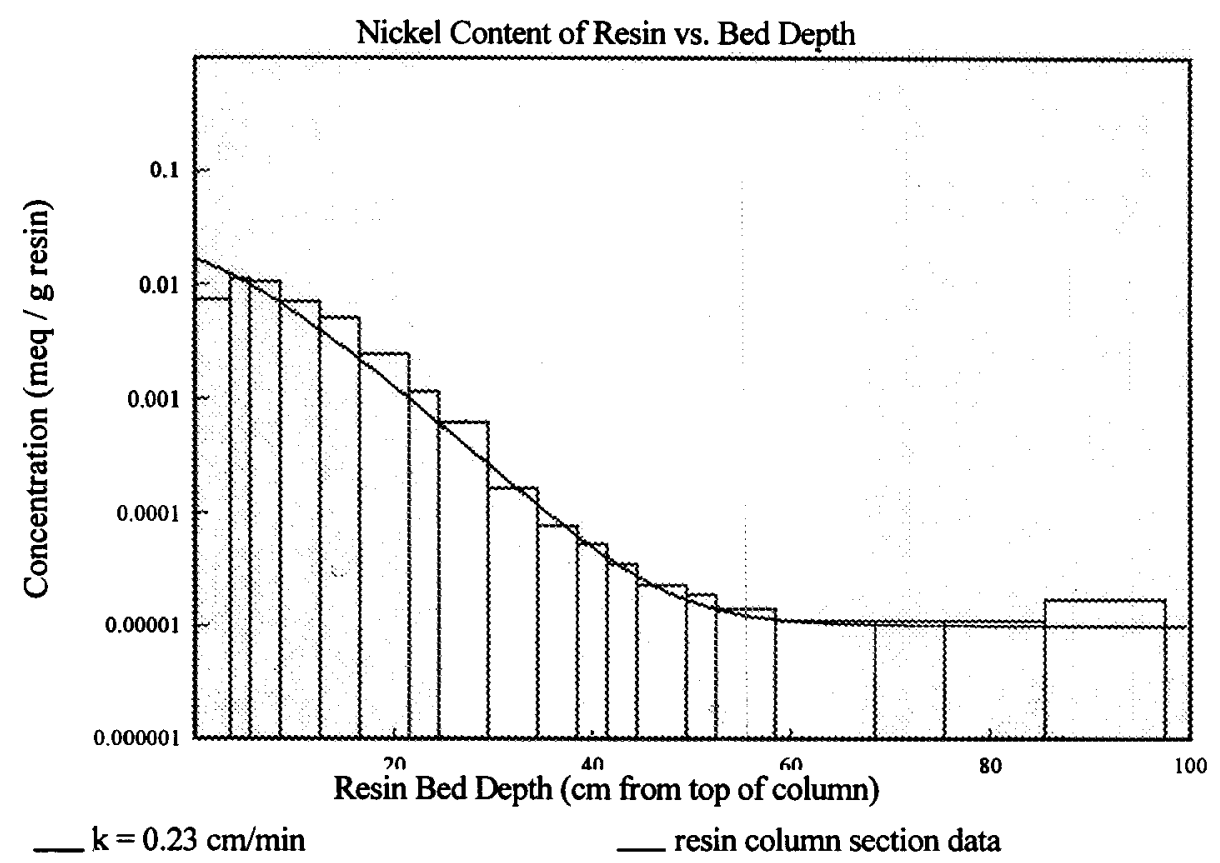

Calculated vs. Measured Nickel Content of Cleanup Column Resin

Superimposed on the sectioning data are the results from SIMIX modeling using the average influent metals concentrations determined above, the Table 2 residual resin metals concentrations, and the mass transfer coefficient calculated from best fit ionic diffusivities. The effective ionic diffusivity for each cation was estimated per the following procedure:

1 A value for D was assumed, and SIMIX was run to produce a fit to the semi-log plot sectioning data.

2. Step 1 was repeated, incrementing the value of $D$ to determine the mass transfer coefficient that minimized the sum of the squares of the residuals. Residual values were the resultant of the log of the measured resin metals concentration subtracted from the log of the corresponding SIMIX predicted value. 


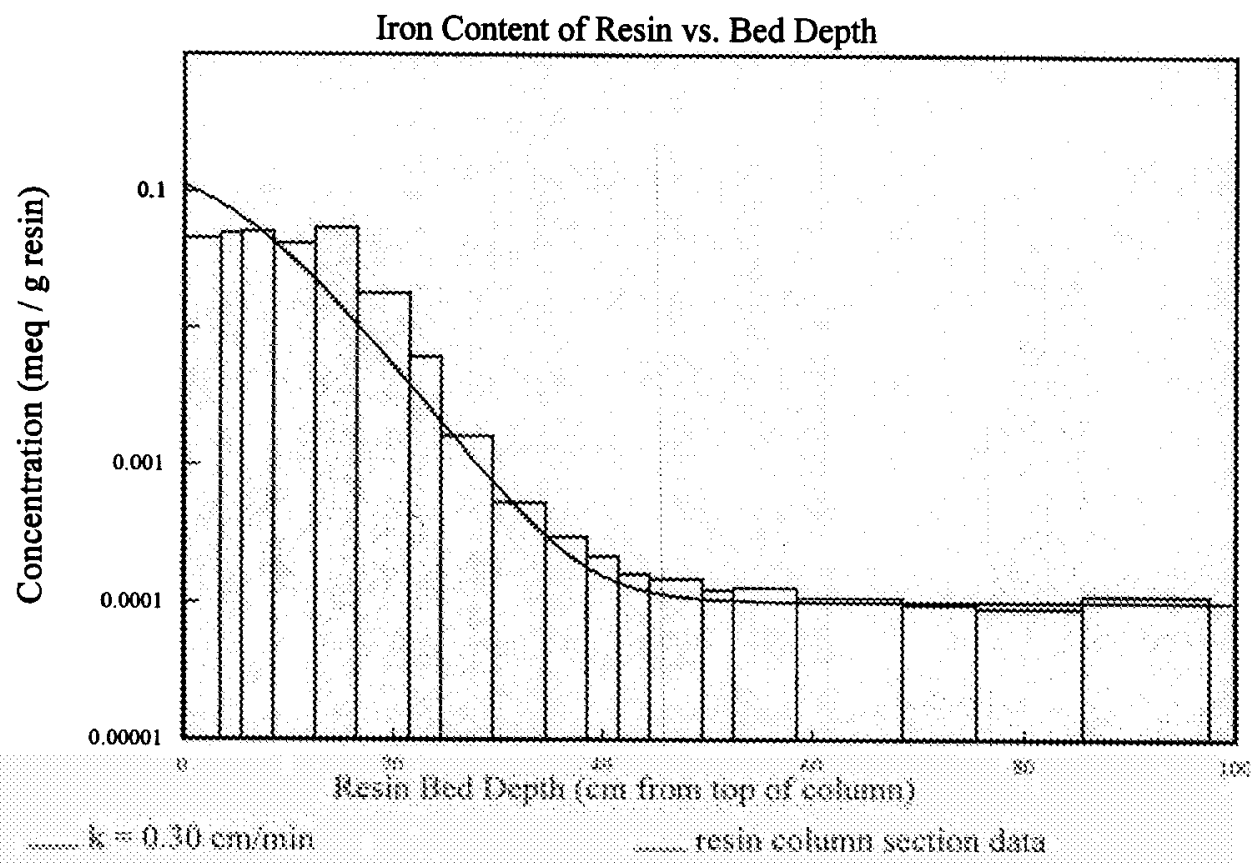

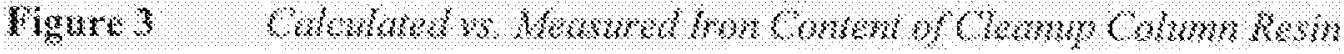

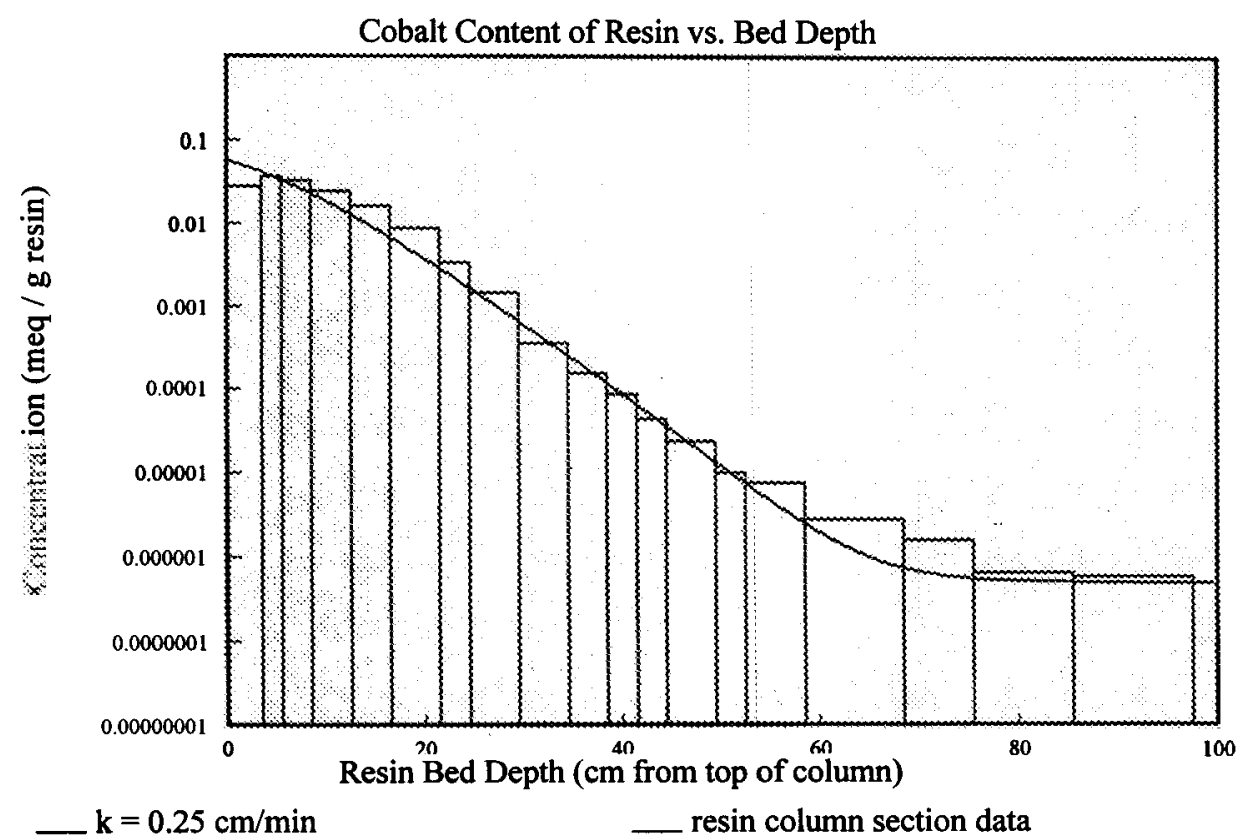

Figure 4 Calculated vs. Measured Cobalt Content of Cleanup Column Resin

\section{CONCLUSIONS}

1. Resin column test results indicate that the active exchange zone in the cleanup column was confined to the upper one third of the bed for all three metal ions. Metal ion concentrations within this zone were modeled with the SIMIX program to obtain best-fit estimates for the ionic diffusivities (D) for nickel, cobalt, and iron cations. Using the 
Dwivedi \& Upadhyay correlation, effective mass transfer coefficients were then calculated as follows:

$$
\begin{array}{ll}
\mathrm{D}_{\mathrm{Ni}}=3.7 \times 10^{-10} \mathrm{~m}^{2} / \mathrm{s} & \left(\mathrm{k}_{\mathrm{L}}\right)_{\mathrm{Ni}}=3.8 \times 10^{-5} \mathrm{~m} / \mathrm{s} \\
\mathrm{D}_{\mathrm{Co}}=4.1 \times 10^{-10} \mathrm{~m}^{2} / \mathrm{s} & \left(\mathrm{k}_{\mathrm{L}}\right)_{\mathrm{Co}}=3.2 \times 10^{-5} \mathrm{~m} / \mathrm{s} \\
\mathrm{D}_{\mathrm{Fe}}=4.8 \times 10^{-10} \mathrm{~m}^{2} / \mathrm{s} & \left(\mathrm{k}_{\mathrm{L}}\right)_{\mathrm{Fe}}=5.0 \times 10^{-5} \mathrm{~m} / \mathrm{s}
\end{array}
$$

2. Below the active exchange zone, measurable cation concentrations were seen in all resin section units, which tapers off to a relatively constant (asymptotic) value in the lower portion of the ion exchanger resin bed. As shown in Table 2, the asymptotic concentrations represent residual metallic cation concentrations in the resin, which were present at the start of testing.

\begin{tabular}{|c|c|c|c|}
\hline \multirow{2}{*}{ Source } & \multicolumn{3}{|c|}{ Metals Concentration (meq/g. mixed resin) } \\
\hline Iron & Nickel & Cobalt \\
\hline test residual & $1.0 \times 10^{-4}$ & $1.0 \times 10^{-5}$ & $5.0 \times 10^{-7}$ \\
\hline unused resin & $2.6 \times 10^{-4}$ & $1.6 \times 10^{5}$ & $2.5 \times 10^{-7}$ \\
\hline
\end{tabular}

Table 2 Ion Exchange Resin Residual Metals Data

\begin{tabular}{|c|c|c|c|}
\hline \multirow{2}{*}{$\begin{array}{c}\text { Method of Calculating } \\
\text { Metals Concentration }\end{array}$} & \multicolumn{3}{|c|}{ Concentration of Metals Influent to Cleanup Columus (pob) } \\
\cline { 2 - 4 } & Nickel Column & Cobalt Column & Iron Column \\
\hline $\begin{array}{c}\text { Cleanup Resin Column } \\
\text { Sectioning Data } \\
\text { (average conc.) }\end{array}$ & $0.24 \pm 0.03$ & $1.41 \pm 0.14$ & $0.8 \pm 0.1$ \\
\hline $\begin{array}{c}\text { Supply Resin Column } \\
\text { Eflluent Data } \\
\text { (mean \& std. dev.) }\end{array}$ & $0.38 \pm 0.25$ & $1.42 \pm 1.11$ & $6.3 \pm 3.6$ \\
\hline
\end{tabular}

Table 3 Cation Supply Column Effluent and Cleanup Test Column Influent Ion Exchange Resin Mass Balance Results

3. A mass balance was performed to compare the amount of metals collected by the cleanup test columns with the total quantity of the metals eluted form the metal ion supply columns. As indicated on Table 3, the two methods for estimating average coolant metals concentration agree within the standard deviation of the chemical analysis results for nickel and cobalt, but not for iron. 


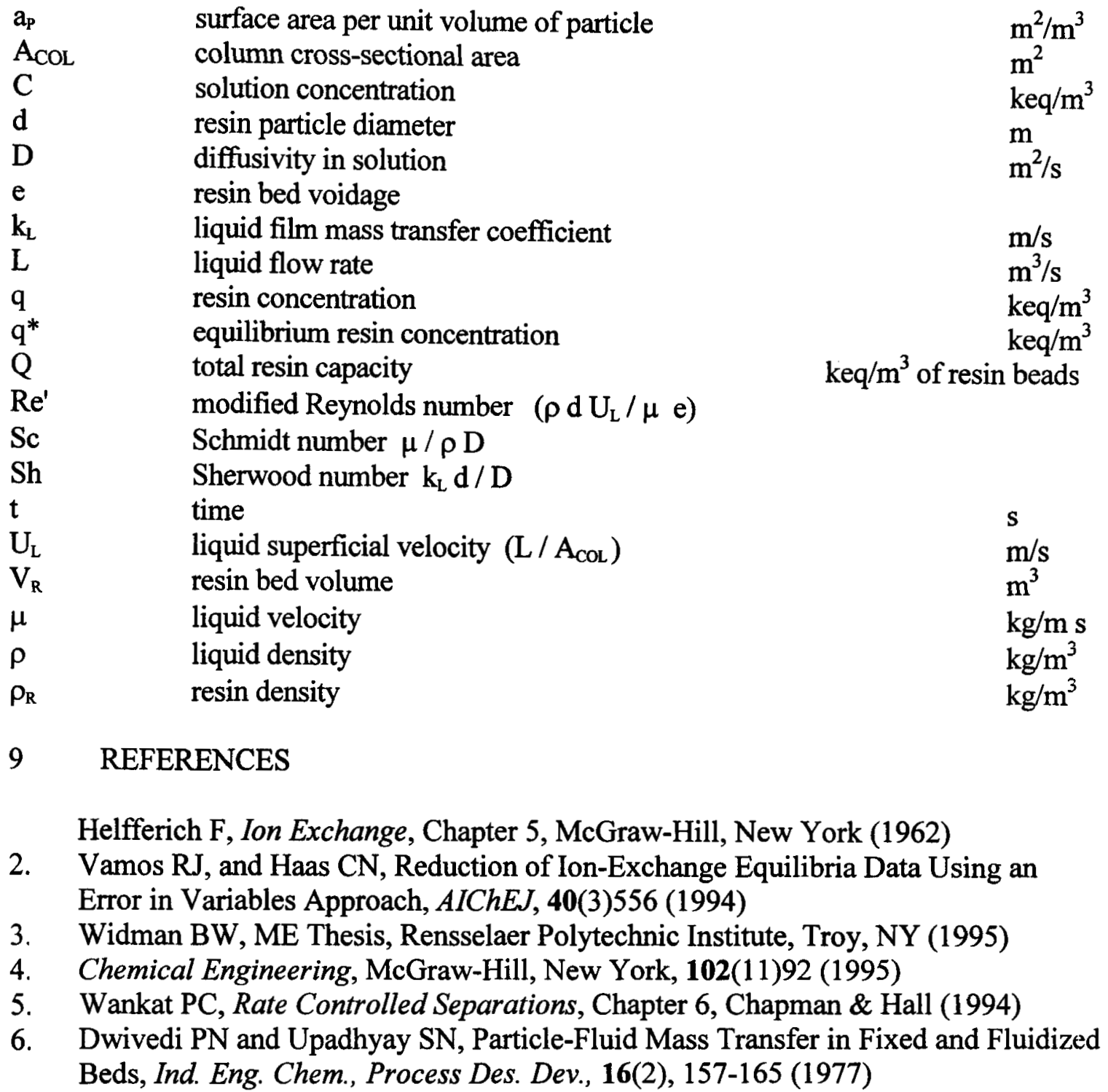

